Correspondence

Professor Flavio Moroni, Department of Preclinical and Clinical Pharmacology, University of Florence, Viale Pieraccini 6, 50139 Firenze, Italy. E-mail: flavio.moroni@unifi.it

Keywords

PARP; stroke; TIQ-A; HYDAMTIQ; neuroprotection; middle cerebral artery occlusion

\section{Received}

13 March 2011

Revised

8 July 2011

Accepted

28 July 2011

\title{
ribose) polymerase
}

\author{
F Moroni $^{1}$, A Cozzi $^{1}$, A Chiarugi ${ }^{1}$, L Formentini $^{1}, \mathrm{E} \mathrm{Camaioni}^{2}$,

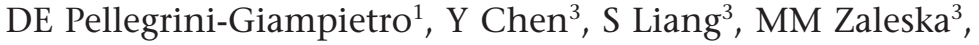 \\ C Gonzales ${ }^{3}$, A Wood ${ }^{3}$ and R Pellicciari ${ }^{2}$ \\ ${ }^{1}$ Department of Preclinical and Clinical Pharmacology, University of Florence, Florence, Italy, \\ ${ }^{2}$ Department of Chemistry and Drug Technology, University of Perugia, Perugia, Italy, and ${ }^{3}$ Pfizer \\ Global Research and Development, Neuroscience Research Unit, Groton, CT, USA
}

\section{BACKGROUND AND PURPOSES}

Thienyl-isoquinolone (TIQ-A) is a relatively potent PARP inhibitor able to reduce post-ischaemic neuronal death in vitro. Here we have studied, in different stroke models in vivo, the neuroprotective properties of DAMTIQ and HYDAMTIQ, two TIQ-A derivatives able to reach the brain and to inhibit PARP-1 and PARP-2.

\section{EXPERIMENTAL APPROACH}

Studies were carried out in (i) transient ( $2 \mathrm{~h}$ ) middle cerebral artery occlusion (tMCAO), (ii) permanent MCAO (pMCAO) and (iii) electrocoagulation of the distal portion of MCA in conjunction with transient (90 min) bilateral carotid occlusion (focal cortical ischaemia).

\section{KEY RESULTS}

In male rats with tMCAO, HYDAMTIQ $\left(0.1-10 \mathrm{mg} \cdot \mathrm{kg}^{-1}\right)$ injected i.p. three times, starting $4 \mathrm{~h}$ after MCAO, reduced infarct volumes by up to $70 \%$, reduced the loss of body weight by up to $60 \%$ and attenuated the neurological impairment by up to $40 \%$. In age-matched female rats, HYDAMTIQ also reduced brain damage. Protection, however, was less pronounced than in the male rats. In animals with PMCAO, HYDAMTIQ administered 30 min after MCAO reduced infarct volumes by approximately $40 \%$. In animals with focal cortical ischaemia, HYDAMTIQ treatment decreased post-ischaemic accumulation of PAR (the product of PARP activity) and the presence of OX42-positive inflammatory cells in the ischaemic cortex. It also reduced sensorimotor deficits for up to 90 days after MCAO.

\section{CONCLUSION AND IMPLICATIONS}

Our results show that HYDAMTIQ is a potent PARP inhibitor that conferred robust neuroprotection and long-lasting improvement of post-stroke neurological deficits.

\section{Abbreviations}

AIF, apoptosis-inducing factor; CBF, cerebral blood flow; MCAO, middle cerebral artery occlusion; DAMTIQ, dimethylaminomethyl- thieno[2,3-c]isoquinolin-5(4H)-one; HYDAMTIQ, hydroxyl-dimethylaminomethylthieno[2,3-c]isoquinolin-5(4H)-one; TIQ-A, thieno[2,3-c]isoquinolin-5(4H)-one; TTC, 2,3,5-triphenyltetrazolium chloride 


\section{Introduction}

Poly(ADP-ribose) polymerases (PARPs) are NAD-dependent enzymes able to catalyse the transfer of ADP-ribose units from NAD to substrate proteins. They are particularly abundant in cell nuclei, may be activated by DNA damage and are involved in the maintenance of genomic integrity, epigenetic regulation of gene expression, control of cell cycle and cell survival (Jagtap and Szabo, 2005). The most studied and best characterized member of this enzyme family is PARP-1, one of the most abundant nuclear proteins responsible for at least $85 \%$ of the maximally stimulated cellular ADP-ribosylating activity (Schreiber et al., 2006). Excellent PARP-1 inhibitors are now available (Ferraris, 2010), and some of them are clinically used for the treatment of various cancers. Beside this widely investigated clinical activity in cancer treatment, PARP-1 inhibitors have also been studied because they reduce post-ischaemic and excitotoxic neuronal death (Eliasson et al., 1997; Endres et al., 1997; Szabo and Dawson, 1998; Moroni et al., 2001; Haddad et al., 2008; Egi et al., 2011). Several mechanisms have been put forward to explain how PARP-1 activation contributes to post-ischaemic brain damage. For instance, excessive activation of this enzyme in neurones may reduce NAD levels, leading to severe ATP shortage, energy failure and cell necrosis (Berger, 1985; Cosi et al., 1994; Ha and Snyder, 1999; Moroni et al., 2001). Also, PARP activation may release apoptosis-inducing factor (AIF) from the mitochondria and facilitate AIF translocation to the nucleus, thus activating a caspase-independent type of apoptosis (Yu et al., 2002). Finally, PARP activation may facilitate the expression of inflammatory mediators (Chiarugi and Moskowitz, 2003), and, when this occurs in macrophages or microglia, the formation of toxic cytokines may increase and neuronal damage may occur (Kauppinen and Swanson, 2005). Other proposed molecular mechanisms linking PARP activation to post-ischaemic brain damage involve a reduced expression of pro-survival factors (Chiarugi, 2002), the formation of a metabolite able to hamper mitochondrial function (Yu et al., 2002; Cipriani et al., 2005), the opening of a transient receptor potential cation channel (TRPM2) and an excessive inflow of $\mathrm{Ca}^{2+}$ due to PAR metabolites (Fonfria et al., 2004) or an enhanced expression of MMP with increased blood-brain barrier permeability and brain oedema (Lenzser et al., 2007). All these molecular mechanisms could contribute to the brain-protective actions of PARP inhibitors that, when administered in vivo, seem to act not only by protecting the neurones but also the other cell types present in the neurovascular unit and damaged by the ischaemic events (endothelia, pericytes, astrocytes, microglia) (see Moroni and Chiarugi, 2009).

Disruption of the PARP-1 gene in mice preferentially protects males from perinatal ischaemic injury (Hagberg et al., 2004), and that PARP inhibitors may even exacerbate ischaemic damage in female brains (McCullough et al., 2005; Yuan et al., 2009), thus cautioning against a possible use of these inhibitors in females. We therefore decided to explore the effects of these agents in both male and female animals.

We have already described and characterized, preliminarily, a series of thieno[2,3-c]isoquinolin-5(4H)-ones (TIQ-A and derivatives) as potent PARP inhibitors that significantly reduce excitotoxic and post-ischaemic neuronal death in primary cultures of rat cortical neurones (Chiarugi et al., 2003; Pellicciari et al., 2003). Recently, the potency, solubility and brain penetration of the TIQ-A series has been significantly improved (Pellicciari et al., 2011), and we report here that these compounds (especially the hydroxyl derivative (hydroxyl-dimethylaminomethyl- thieno[2,3-c]isoquinolin5(4H)-one); HYDAMTIQ), administered up to $4 \mathrm{~h}$ after $\mathrm{MCAO}$, significantly reduced infarct volumes and postischaemic neurological impairment. Protection was associated with reduced brain content of PAR (the product of PARP action) and reduced numbers of OX42-positive inflammatory cells in the affected cortical areas. Experiments have been carried out in two independent laboratories working in different rat strains (Wistar and Sprague-Dawley), in different stroke models (transient and permanent occlusion of MCA) and, as previously mentioned, in both male and female animals.

\section{Methods}

\section{Assay of PARP-1, PARP-2 and tankyrase-1 activity and inhibition studies}

PARP activity was evaluated utilizing commercially available recombinant bovine PARP-1 and mouse PARP-2 as described by Moroni et al., (2009). Briefly, the enzymic reaction was carried out in a final volume of $100 \mu \mathrm{L}$, consisting of $20 \mathrm{mM}$ Tris- $\mathrm{HCl}$ (pH 8.0), $20 \mathrm{mM} \mathrm{MgCl}_{2}, 5 \mathrm{mM}$ dithiothreitol (DTT), $20 \mu \mathrm{g}$ sonicated calf thymus DNA, $0,2 \mu \mathrm{Ci}$ [adenine-2, $\left.8-{ }^{3} \mathrm{H}\right] \mathrm{NAD}$ and recombinant enzyme PARP-1 or PARP-2 (0.03 U per sample). Different concentrations of the putative inhibitors were added, and the mixture was incubated for $1 \mathrm{~h}$ at $37^{\circ} \mathrm{C}$. The reaction was terminated by adding $500 \mu \mathrm{L}$ of $50 \%$ trichloroacetic acid and centrifuged. After two gentle washes of the pellet with $1 \mathrm{~mL}$ distilled water, the radioactivity incorporated from [adenine-2,8- ${ }^{3} \mathrm{H}$ ]NAD into proteins was evaluated by liquid scintillation spectrometry.

Tankyrase-1 function was monitored in HeLa cells cultured in Dulbecco's modified Eagle's medium (DMEM) and synchronized in mitosis as previously described (Moroni et al., 2009).

The enzyme nomenclature we have used here is under debate (Hottiger et al., 2010), but the abbreviation PARP follows Alexander et al., (2011).

\section{Experiments in vivo}

All the experiments conducted in Italy were carried out according to the Italian guidelines for animal care (DL 116/ 92) in application of the European Communities Council Directive (86/609/EEC) and were formally approved by the Animal Care Committee of the Department of Pharmacology of the University of Florence. Sprague-Dawley rats, aged 9-10 weeks (males weight 280-300 g; female weights 200-220 g), were from Charles River (Calco, LC, Italy). The experiments conducted at Pfizer (formerly Wyeth) in the United States were conducted according to protocols approved by the Institutional Animal Care and Use Committee. In these studies, male Wistar rats, 270-290 g (age 8-9 weeks), from Charles River (Raleigh, NC, USA) were used. The different in vivo 


\begin{tabular}{|llll|}
\hline Group & Surgery & Strain and sex & Time of evaluation after MCAO \\
\hline 1 & tMCAO & Sprague-Dawley males & $48 \mathrm{~h}$ \\
2 & TMCAO & Sprague-Dawley males & 7 days \\
3 & PMCAO & Sprague-Dawley males & $24 \mathrm{~h}$ \\
4 & tMCAO & Sprague-Dawley females & $48 \mathrm{~h}$ \\
5 & Cortical focal ischaemia & Wistar males & $24-48 \mathrm{~h}$ for PAR measurements and cell counts \\
6 & Cortical focal ischaemia & Wistar males & 21 days for immunohistochemistry \\
7 & Cortical focal ischaemia & Wistar males & 92 days for behaviour \\
\hline
\end{tabular}

tMCAO (the period of occlusion was $2 \mathrm{~h}$ ); Cortical focal ischaemia comprised the direct electrocauterization of the distal portion of the MCA in conjunction with ligation of both common carotid arteries for $90 \mathrm{~min}$.

experimental approaches we used in the present research are listed in Table 1.

\section{Middle cerebral artery occlusion (tMCAO and pMCAO) in rats}

A relatively non-invasive technique (Longa et al., 1989) was utilized for MCAO in Sprague-Dawley rats as previously described (Giovannelli et al., 2002). In these experiments, the animals were randomly picked up from the cages and allocated to the vehicle or treated groups. The researchers were aware of the treatment allocation. Anaesthesia was induced with $2 \%$ isoflurane in air and maintained with the lowest active concentration of anaesthetic. Body temperature was measured with a rectal probe and kept at $37^{\circ} \mathrm{C}$ with a heating pad. The external and internal right carotid arteries were dissected under an operating microscope, and a silk suture was placed loosely around them. The common carotid artery was then temporarily occluded. This closure was maintained during the $2 \mathrm{~h}$ of MCAO. A silicon-coated nylon filament (diameter $0.28 \mathrm{~mm}$ ) with a flame-rounded tip was then inserted through the external into the internal carotid artery up to the Circle of Willis to occlude the right MCA. The silk suture placed around the external carotid was tightened to prevent bleeding. A laser Periflux 5000 Doppler system (Perimed, Stockholm, Sweden) connected to a 418-1 probe, attached to the skull on the temporal bone near the suture with the parietal bone and approximately $2 \mathrm{~mm}$ posterior of bregma, was used to monitor regional cerebral blood flow (rCBF) before ischaemia, during MCAO (2 h) and after reperfusion. The $\mathrm{MCAO}$ was considered adequate if rCBF decreased to $25 \%$ of the baseline level (baseline was considered the rCBF before the occlusion of the common carotid that, by itself, decreased CBF by approximately 30\%). CBF was constantly monitored during the experimental procedure, and rats were utilized only if the average CBF in the region, during the $2 \mathrm{~h}$ ischaemic period, decreased by at least $70 \%$ and recovered to approximately the basal levels $( \pm 10 \%)$ within a few minutes after the withdrawing of the filament and the re-opening of the common carotid. In separate experiments, we prepared animals with the same procedure, but we did not remove the nylon filament (permanent occlusion, pMCAO). In this severe pMCAO model, the animals were killed $24 \mathrm{~h}$ after surgery (group 3).

\section{Cortical focal ischaemia model}

Adult male Wistar rats (270-310 g) were randomly allocated to treatment groups ( $n=10$ per group). Surgical occlusion, assessment of neurological deficits and histology were all performed by researchers unaware of treatment allocation. Rats were anaesthetized using 3\% isoflurane in 70\% nitrous oxide : $30 \%$ oxygen. In this model, permanent occlusion was induced by electrocauterization of the distal portion of the MCA (Chen et al., 1986) in conjunction with ligation of both common carotid arteries for $90 \mathrm{~min}$. Core body temperature was maintained at $37^{\circ} \mathrm{C}$ throughout the surgery using a heating lamp. CBF in the MCA territory was recorded by laser Doppler flowmetry (Perimed) attached to the skull near the suture between the temporal and parietal bones and approximately $2 \mathrm{~mm}$ posterior of bregma from $10 \mathrm{~min}$ prior to and 5 min post-induction of ischaemia. An 85\% reduction of CBF was achieved in all animals. This procedure resulted in a consistent infarction in the area of sensorimotor cortex governing forelimb and hind limb function and allowed for long-term assessment of neurological outcomes. Sham surgery included craniotomy without cauterization of the MCA. A total of 47 rats were used. Seven of them died from surgery-related events in the first few hours after MCAO but none of them died after the beginning of i.v. infusion with either saline or HYDAMTIQ (4 h later).

\section{Drug administration protocol}

TIQ-A was synthesized as previously reported (Pellicciari et al., 2003); dimethylaminomethyl- thieno[2,3c]isoquinolin-5(4H)-one (DAMTIQ) and HYDAMTIQ were synthesized as described in Pellicciari et al. (2011). The compounds were $>97 \%$ pure as assessed by HPLC. TIQ-A and DAMTIQ were dissolved and diluted in dimethyl sulphoxide (DMSO) and injected i.p. in a volume of $50 \mu \mathrm{L}$; HYDAMTIQ (as hydrobromide or hydrochloride salt) was dissolved in saline. Control animals received an equal amount of vehicle (either DMSO or saline). For $24 \mathrm{~h}$ i.v. infusion of HYDAMTIQ in Wistar rats, PE-50 tubing was placed in the femoral vein. 
The tubing was tied into place and threaded under the skin to emerge from the back of the neck. It was attached to a swivel connected to a Hamilton syringe and a pump (Harvard Apparatus). Drug or saline was administered via the catheter at the rate of $0.25 \mathrm{~mL} \cdot \mathrm{h}^{-1}$ for $24 \mathrm{~h}$ after an i.v. bolus of $3.5 \mathrm{mg} \cdot \mathrm{kg}^{-1}$ beginning $4 \mathrm{~h}$ post-MCAO (see Table 1 , groups $5-7$ ).

\section{Evaluation of infarct volumes}

Animals were killed at different time after MCAO, and their brains were snap-frozen in $\mathrm{N}_{2}$ vapour for cryostat sectioning. Haematoxylin-eosin-stained coronal sections were imaged by using the Image 3.0 ProPlus (Silver Spring, MD, USA) analysis software. Ten sections, each taken $1 \mathrm{~mm}$ apart, were analysed. Infarct areas were calculated subtracting the area of intact tissue in the ipsilateral hemisphere from the area of the contralateral hemisphere to minimize the error that is introduced by oedema, which distorts and enlarges the infarcted tissue and surrounding white matter. Infarct volumes were calculated by multiplying the infarct areas by the distance between sections as previously described (Giovannelli et al., 2002; Cozzi et al., 2006). In preliminary experiments, $24 \mathrm{~h}$ after surgery, the rats were again anaesthetized (chloral hydrate $400 \mathrm{mg} \cdot \mathrm{kg}^{-1}$ ), the chest was opened and $5 \mathrm{~mL}$ of a solution containing 2\% 2,3,5-triphenyltetrazolium chloride (TTC) in saline was slowly injected into the left cardiac ventricle. Brains were removed 20 min later and placed in 4\% formalin. Within 2 days, $1 \mathrm{~mm}$-thick coronal sections were prepared, and the infarct areas measured using a computerized image analysis system (Image ProPlus 3.0). After measuring the surface area in ten slices, the infarct volume was calculated as previously reported (Moroni et al., 2002). No statistically significant differences were observed in the ischaemic infarct volumes between the TTC and the haematoxylin-eosin staining approaches.

\section{Neurological evaluation}

tMCAO. Animals were weighed before surgery and every $24 \mathrm{~h}$ thereafter. Neurological evaluation was carried out according to a modification of the procedures described by Bederson et al. (1986). A simple yes or no response was determined for the following signs: (i) flexion of the contralateral forelimb: Rats were held gently by the tail suspended above the floor and observed for forelimb flexion. Normal rats extend both forelimbs towards the floor. Rats with infarction consistently flexed the forelimb contralateral to the injured hemisphere. (ii) Twisting of the torso: when the rats were held by the tail, the presence of flexion of wrist and elbow, with adduction or internal rotation of the shoulder toward the paretic side was recorded. (iii) Decreased resistance to lateral push: rats were placed on the floor and were gently pushed from side to side. The test was repeated several times in each direction. Normal (or mildly dysfunctional) rats resisted sliding equally in both directions. Lesion-bearing rats had consistently reduced resistance to lateral push towards the paretic side. (iv) Circling when holding the tail allowing the forelimbs to make contact with the floor: Lesion-bearing rats circled towards the paretic side. (v) Spontaneous circling: rats that spontaneously circled towards the paretic side consistently were considered neurologically impaired. (vi) Lack of response was considered immobility. Each animal was scored 1 point for each of the above-mentioned behaviours ( 0 point: normal; 5 points: complete paresis).

Cortical focal ischaemia. Rats were evaluated for neurological impairments for up to 90 days following ischaemia using several tests. Postural (body swing and forelimb paresis) and hind limb placement tests (Bederson et al., 1986) as well as sensorimotor integration and reflex-driven forelimb placement responses to visual and tactile stimuli tests (De Ryck et al., 1989) were assessed. A maximum severity neurological deficit score for the combined procedures was 12 . Naive or sham-operated animals displayed no deficits (a score of 0 ).

\section{Poly ADP-ribose (PAR) determination}

PAR was measured in brains derived from Wistar rats subjected to MCAO and treated with an i.v. bolus injection of $3.5 \mathrm{mg} \cdot \mathrm{kg}^{-1}$ HYDAMTIQ followed by infusion of $2.5 \mathrm{mg} \cdot \mathrm{kg} \cdot \mathrm{h}^{-1}$ for $24 \mathrm{~h}$. Brain samples (approximately $100 \mathrm{mg}$ taken from the cortex for Figure 9A or the entire hemisphere for Figure 9B) were rinsed in PBS and then suspended in hypotonic lysis buffer containing DTT and protease inhibitors (Sigma, St Louis, MO, USA). After homogenization and centrifugation $(20 \mathrm{~min}$ at $10000 \times \mathrm{g})$, the nuclear pellet was re-suspended in extraction buffer containing DTT and protease inhibitors and gently shaken for $30 \mathrm{~min}$. After a further centrifugation $(5 \mathrm{~min}$ at $20000 \times \mathrm{g}$ ), the supernatants were snap-frozen in liquid nitrogen and stored at $-80^{\circ} \mathrm{C}$ until tested according to Liu et al. (2008). Briefly, we used Pierce Reacti-Bind plates (CN 15042) coated with anti-PAR monoclonal antibody (Trevigen, Gaithersburg, MD, USA; cat. \#4335-MC-100) diluted $1: 500$ in $0.1 \mathrm{M}$ carbonate buffer $\left(8.4 \mathrm{~g} \cdot \mathrm{L}^{-1} \mathrm{NaHCO}_{3}\right.$ and $3.56 \mathrm{~g} \cdot \mathrm{L}^{-1} \mathrm{Na}_{2} \mathrm{CO}_{3}, \quad \mathrm{pH}$ 9.6) at $100 \mu \mathrm{L}$.per well for $2 \mathrm{~h}$ at $37^{\circ} \mathrm{C}$. Plates were washed five times with PBS containing $0.1 \%(\mathrm{v} / \mathrm{v})$ Tween-20 and blocked with $2 \%$ BSA in PBS for $1 \mathrm{~h}$. PAR standards and samples were diluted in PBS containing 2\% BSA, 0.5\% (w/v) SDS and loaded in a final assay volume of $75 \mu \mathrm{L}$. Plates were incubated at $4^{\circ} \mathrm{C}$ overnight then washed five times with PBS containing $0.1 \%$ Tween-20. Polyclonal anti-PAR antibody (Trevigen; cat. \#4336-BPC-100) diluted 1:500 in PBS containing 2\% BSA and mouse serum was added to the plates that were incubated for $2 \mathrm{~h}$ at room temperature and then washed five times with PBS/0.1\% Tween-20. Goat anti-rabbit HRP (KPL, Gaithersburg, MD, USA) (100 $\mu \mathrm{L}$-per well) diluted in a mixture containing PBS, 2\% BSA and diluted mouse serum (1:500) was then added, and the plates were incubated at room temperature for $1 \mathrm{~h} ; 100 \mu \mathrm{L}$-per well luminescent substrate was added, and luminescence was measured with a SpectraMax M5 (Molecular device, Sunnyvale, CA, USA). All samples were normalized for total protein.

\section{Immunohistochemistry}

Animals treated with saline or HYDAMTIQ were killed at 21 days after induction of ischaemia. The brains were removed, fixed in $4 \%$ paraformaldehyde at $37^{\circ} \mathrm{C}$ for $24 \mathrm{~h}$ and then transferred to $30 \%$ sucrose. Representative coronal sections $(25 \mu \mathrm{m})$ were obtained using a rotary microtome (Leica RM2145, Salm, Germany). Sections were incubated overnight at $4^{\circ} \mathrm{C}$ with one of the following antibodies: anti-CD11 (OX42; 1:200, Cedarlane, Canada); mouse anti-PAR; 1:200 
<smiles>O=c1[nH]c2sccc2c2ccccc12</smiles>

TIQ-A<smiles>CN(C)Cc1cc2c([nH]c(=O)c3ccccc32)s1</smiles>

DAMTIQ<smiles>CN(C)Cc1cc2c([nH]c(=O)c3cccc(O)c32)s1</smiles>

HYDAMTIQ

\begin{tabular}{|l|c|c|c|}
\hline \multicolumn{1}{|c|}{ IC $_{\mathbf{5 0}}(\mathbf{n M})$} & TIQ-A & DAMTIQ & HYDAMTIQ \\
\hline PARP-1 & 500 & $89 \pm 9$. & $20 \pm 0.09$ \\
\hline PARP-2 & 600 & $300 \pm 10$ & $38 \pm 0.04$ \\
\hline Tankyrase 1 & $>100 \mu \mathrm{M}$ & $>100 \mu \mathrm{M}$ & $>100 \mu \mathrm{M}$ \\
\hline
\end{tabular}

Figure 1

Molecular structures and potencies as enzyme inhibitors in vitro (shown as IC 50 values; $\mathrm{nM}$; means \pm SEM) of the three thienyl-isoquinolones studied here (TIQ-A, DAMTIQ and HYDAMTIQ).

(BD Biosciences, Franklin Lakes, NJ, USA); NeuN monoclonal antibody (cat. MAB 377; Chemicon International; Billerica, MA, USA). After washing, a fluorescent-conjugated secondary antibody (1:2000, Alexa Fluor 488 or 594, Molecular Probes, Eugene, OR) was applied, and sections were mounted using Vectashield medium (Vector Labs, Burlingame, CA, USA). TUNEL labelling was performed to identify DNA fragmentation. At 21 days after cortical focal ischaemia, randomly selected brains derived from ischaemic animals treated with saline or HYDAMTIQ were cut into coronal sections $(25 \mu \mathrm{m})$ and stained using the in situ Cell Death detection kit, Fluorescein or TMR red (Roche Applied Science, Penzberg, Germany). Nine sections per animal were mounted, and all the immunopositive cells were individually counted in each section by an observer, unaware of the treatments, with an Axiovert 135 fluorescent microscope (Zeiss, Jena, Germany) and Axiocam camera (Zeiss) using Axiovison 4.5 software. The region evaluated was the dorsal cortex adjacent to the ischaemic lesion.

\section{Data analysis}

Data were analysed with GraphPad Prism 5 (La Jolla, CA, USA). Infarct volumes are presented using box and whisker plots (box is first and third quartile with median and whisker is the range) and analysed using one-way ANOvA followed by the Tukey-Kramer multiple comparison test. The MannWhitney non-parametric test was used to analyse the neuro- logical scores. Other data were reported either as means \pm SEM or means \pm SD (Figure $5 \mathrm{~A}$ ), as indicated in the legends.

\section{Results}

\section{Characterization of TIQ-A, DAMTIQ and HYDAMTIQ}

We previously reported the design, synthesis and preliminary characterization of thieno[2,3-c]isoquinolin-5(4H)-one (TIQ-A) as potential anti-ischaemic agent. The scaffold of TIQ-A bears the minimal pharmacophore that is required for PARP inhibition. The compound was endowed with good potency at inhibiting the catalytic activity of PARP-1 in vitro and in inhibiting post-ischaemic brain damage in cultured neurones and in vivo (Chiarugi et al., 2003; Pellicciari et al., 2003). Figure 1 shows the chemical structures of TIQ-A and its derivatives DAMTIQ or HYDAMTIQ that were synthesized, on the basis of the structural information of the PARP-1 catalytic site, with the aim of improving potency, solubility and cellular penetration. The figure also shows that the compounds had similar affinity for both PARP-1 and PARP-2. In particular, HYDAMTIQ had an $\mathrm{IC}_{50}$ of $20 \mathrm{nM}$ against PARP- 1 and of $38 \mathrm{nM}$ against PARP-2. In order to rule out a possible interaction with tankyrase-1, we assessed the telomere function of this enzyme in HeLa cells by counting the number of abnormal spindles and mitosis during cell division. It has 


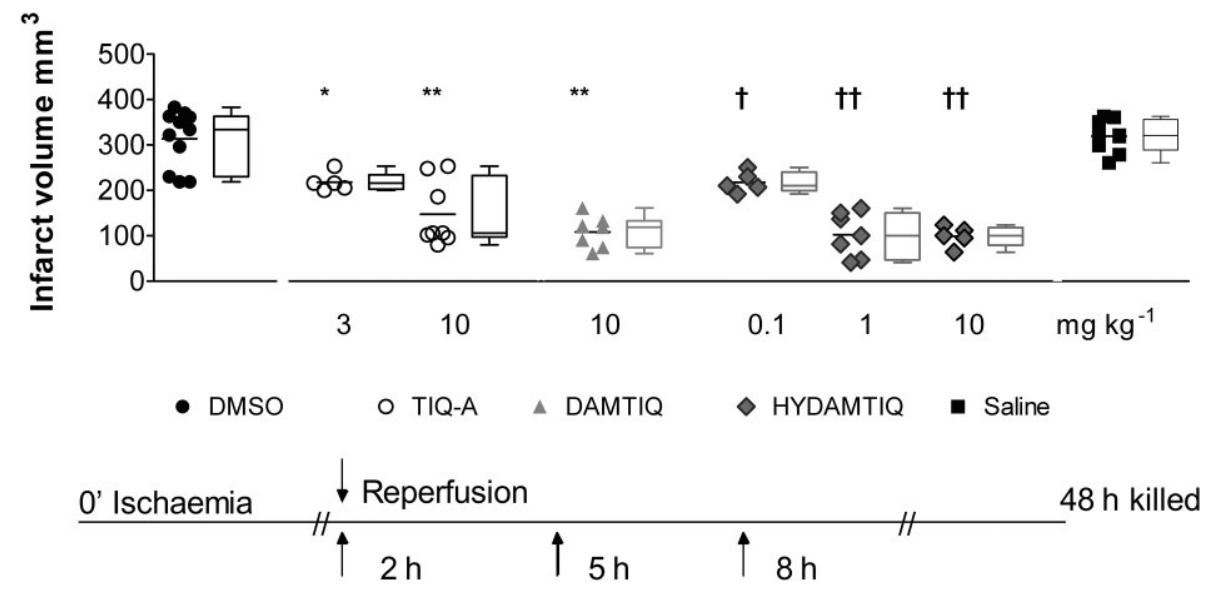

\section{Figure 2}

Infarct volumes in Sprague-Dawley male rats after tMCAO (group 1): neuroprotective effects of TIQ-A, DAMTIQ and HYDAMTIQ administered i.p. $2 \mathrm{~h}$ after artery occlusion. The lower panel shows the experimental protocol, and the arrows show the reperfusion and the time of i.p. inhibitor administration. The upper graphs show raw data and the derived box and whisker plots. The box is first and third quartile with median shown as a horizontal bar; the whiskers are the range. As TIQ-A and DAMTIQ were dissolved in DMSO and HYDAMTIQ was dissolved in saline, the first and the last group are the relevant vehicle-treated animals. Values were obtained in surviving rats. Mortality was: 1 out of 12 animals in the DMSO and 1 out of 10 in the saline group; 2 out of 10 rats died in the TIQ-A $10 \mathrm{mg} \cdot \mathrm{kg}^{-1}$ and 1 out of 8 in the HYDAMTIQ $1 \mathrm{mg} \cdot \mathrm{kg}^{-1} \mathrm{group}$. No mortality occurred in the other groups. ANOVA and Tukey-Kramer multiple comparisons test. ${ }^{*} P<0.01$ and ${ }^{* *} P<0.001$, significantly different from DMSO group; $\uparrow P<0.01$ and $\dagger \dagger P<0.001$, significantly different from saline.

been shown that a reduction of tankyrase-1 activity by RNAi leads to the formation of multipolar spindles and to abnormal mitosis (Moroni et al., 2009). Whereas RNAi against tankyrase-1 or the non-specific PARP inhibitor benzamide promotes the appearance of a significant number of multipolar mitoses, neither TIQ-A nor its derivatives, when used at concentrations $(100 \mu \mathrm{M})$ that are much higher than those required to inhibit PARP-1 or PARP-2, interfered with the telomeric function of tankyrase-1 (Moroni et al., 2009). The compounds were effective in improving the survival of primary cultures of neuronal cells exposed to oxygen and glucose deprivation, in reducing the loss of ATP content of HeLa cell lines exposed to DNA damaging agents and in reducing infarct volumes in preliminary experiments (Pellicciari et al., 2011). The most interesting compound, HYDAMTIQ, was also tested against a panel of 62 receptors and enzymes at a concentration of $10 \mu \mathrm{M}$ (NOVASCREEN) and showed an excellent selectivity: beside PARP-1 and PARP-2, the only other target marginally affected was the 5HT transporter $\left(\mathrm{IC}_{50} 6 \mu \mathrm{M}\right)$ (Pellicciari et al., 2011). In preliminary pharmacokinetic experiments in Wistar rats, the administration of an i.v. bolus of $3,5 \mathrm{mg} \cdot \mathrm{kg}^{-1}$ followed by constant infusion of $2.5 \mathrm{mg} \cdot \mathrm{kg} \cdot \mathrm{h}^{-1}$ for $24 \mathrm{~h}$ resulted in HYDAMTIQ plasma and brain levels of 1.3 and $0.78 \mu \mathrm{M}$, respectively, considered sufficient to reduce PARP activity in brain.

\section{TIQ-A, DAMTIQ and HYDAMTIQ reduce the vulnerability to ischaemic brain injury of male rats subjected to $\mathrm{tMCAO}$}

As PARP-1 gene deletion and a number of PARP-inhibitors have previously been reported to reduce post-ischaemic brain damage, in the present series of experiments, we decided to investigate the extent of this protection after dif- ferent doses of the inhibitors and the possibility of delaying the beginning of the treatment after the occlusion of the MCA. Rectal temperature, mean arterial blood pressure, $\mathrm{pH}$, $\mathrm{PaO} 2$ and $\mathrm{PaCO} 2$ did not differ between animals treated with vehicle and those treated with the larger dose $\left(10 \mathrm{mg} \cdot \mathrm{kg}^{-1}\right.$, i.p.) of PARP-inhibitor, for $1 \mathrm{~h}$ after the first dose of drug administration (not shown). Mortality rate in these experiments was lower than $10 \%$ and did not differ between controls and treated animals (see Figure legends). Measurement of brain infarct volumes $48 \mathrm{~h}$ after MCAO revealed that when the PARP inhibitors were injected $2 \mathrm{~h}$ after the occlusion (immediately before the reperfusion) and twice thereafter (a total of three injections in the first $8 \mathrm{~h}$ after the occlusion), the reduction of necrotic areas and volumes were very clear: TIQ-A or DAMTIQ at $10 \mathrm{mg} \cdot \mathrm{kg}^{-1}$ reduced the infarct volumes by approximately $70 \%$ (Figure 2 ). This Figure also shows that HYDAMTIQ, administered with an identical time schedule, significantly reduced brain infarct volumes starting at a dose of $0.1 \mathrm{mg} \cdot \mathrm{kg}^{-1}$ with a maximum effect (approximately $75 \%$ protection) at $1 \mathrm{mg} \cdot \mathrm{kg}^{-1}$. No further improvement was obtained when the dose was increased to $10 \mathrm{mg} \cdot \mathrm{kg}^{-1}$.

When the first administration of PARP inhibitors was delayed, to $4 \mathrm{~h}$ after the beginning of the MCAO $(2 \mathrm{~h}$ after reperfusion), both DAMTIQ (10 $\mathrm{mg} \cdot \mathrm{kg}^{-1}$ i.p.) and HYDAMTIQ (0.1-10 mg. $\mathrm{kg}^{-1}$ i.p.) significantly reduced brain damage, but the reduction of the infarct volumes was 33\% for DAMTIQ $\left(10 \mathrm{mg} \cdot \mathrm{kg}^{-1}\right)$ and $65 \%$ for HYDAMTIQ $\left(1 \mathrm{mg} \cdot \mathrm{kg}^{-1}\right.$ ) (Figure 3 ).

It was interesting to observe that HYDAMTIQ administered $4 \mathrm{~h}$ after MCAO attenuated the body weight loss observed in the first two days after the procedure. The weight loss, relative to the body weight immediately before MCAO $(100 \%)$, was $19 \pm 2 \%$ in the saline treated animals and $12.7 \pm$ $3.1 \%$ (N.S); $7.5 \pm 1.4 \%(\mathrm{P}<0.01)$ and $10 \pm 1.9 \%(\mathrm{P}<0.05)$ in 

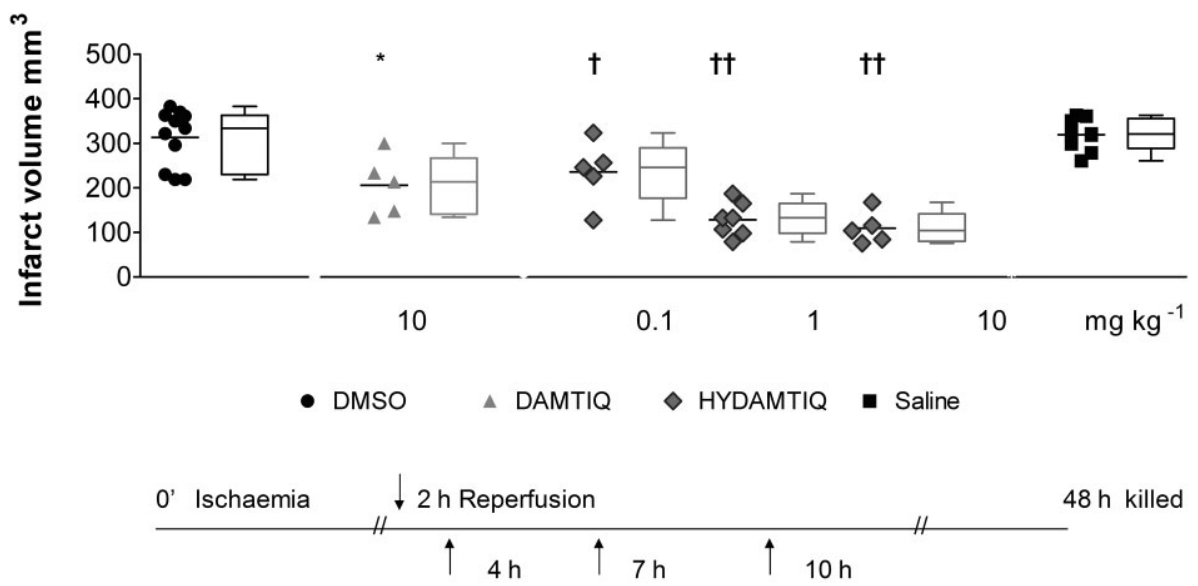

\section{Figure 3}

Infarct volumes in Sprague-Dawley male rats after tMCAO (group 1): neuroprotective effects of DAMTIQ or HYDAMTIQ administered i.p. 4 h after artery occlusion. The lower panel shows the experimental protocol; the arrows show the reperfusion and the time of i.p. inhibitor administration. The upper graphs show raw data and and the derived box and whisker plots, defined as in Figure 1. As DAMTIQ was dissolved in DMSO and HYDAMTIQ was dissolved in saline, the first and the last group are the vehicle controls for DAMTIQ and HYDAMTIQ respectively. Values were obtained in surviving rats. Mortality was 1 out of 12 animals in the DMSO; 1 out of 10 in the saline and 1 out of 6 in the HYDAMTIQ 10 mg.kg ${ }^{-1}$ group. No mortality occurred in the other groups. ANOVA and Tukey-Kramer multiple comparisons test. ${ }^{*} P<0.01$ significantly different from DMSO; $\dagger P<0.05$ and $\dagger \dagger P<0.001$ significantly different from saline.

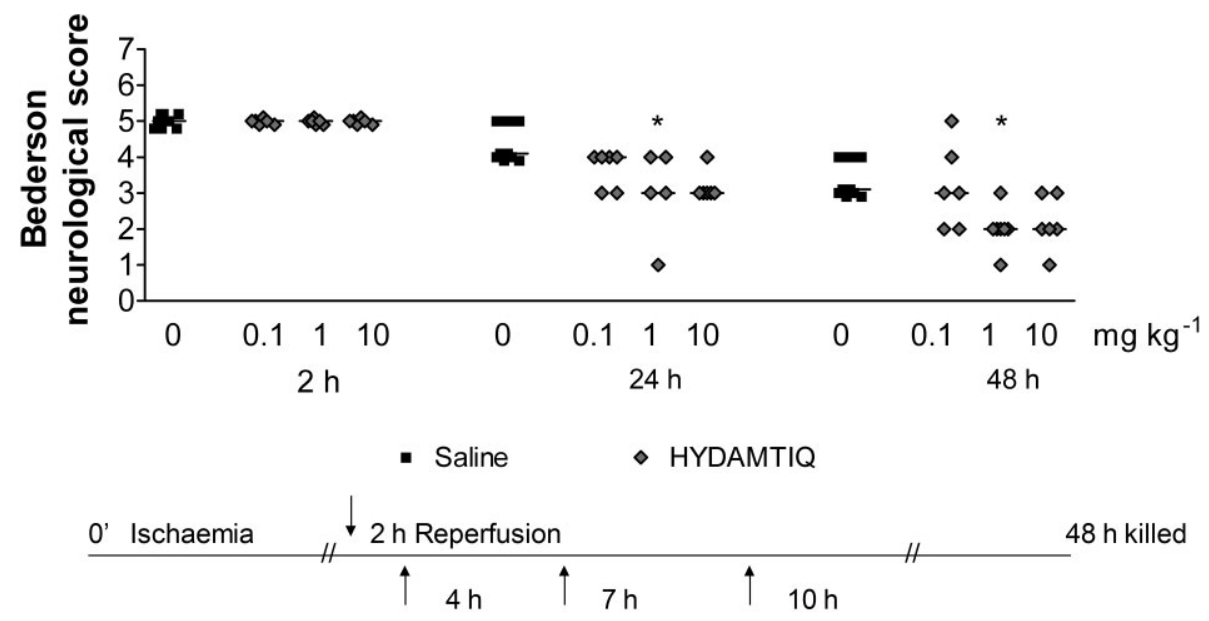

\section{Figure 4}

HYDAMTIQ treatment ( $1 \mathrm{mg} \cdot \mathrm{kg}^{-1}$ i.p. beginning $4 \mathrm{~h}$ after artery occlusion) reduces neurological impairment 24 and $48 \mathrm{~h}$ after surgery in Sprague-Dawley male rats with tMCAO (group 1). The lower panel shows the experimental protocol; the arrows show the reperfusion and the time of i.p. inhibitor administration. ANOVA and Tukey-Kramer multiple comparisons test. ${ }^{*} P<0.05$, significantly different from saline.

animals treated with $0.1,1$ or $10 \mathrm{mg} \cdot \mathrm{kg}^{-1}$ i.p. of HYDAMTIQ respectively. Figure 4 shows that HYDAMTIQ $\left(1 \mathrm{mg} \cdot \mathrm{kg}^{-1}\right.$ i.p. $)$ significantly reduced the neurological deficits evaluated in these animals at 24 and $48 \mathrm{~h}$ after MCAO.

In order to rule out the possibility that PARP inhibition simply delays brain damage, a group of male SpragueDawley rats with tMCAO was treated with DAMTIQ (10 mg. $\mathrm{kg}^{-1}$ i.p.) starting $4 \mathrm{~h}$ after the beginning of artery occlusion and evaluated 7 days after surgery (group 2; Table 1). Figure 5 shows that treated animals had reduced brain infarct volumes and better neurological scores than the vehicle-treated group.
TIQ-A, DAMTIQ and HYDAMTIQ reduce the vulnerability to ischaemic brain injury of male rats subjected to $\mathrm{PMCAO}$

Permanent occlusion of the MCA (and of most of collateral circle) with the suture method causes a rather large brain infarct $\left(420 \pm 35 \mathrm{~mm}^{3}\right)$ and a relatively high mortality rate in the first $24 \mathrm{~h}$ after surgery (up to 20\% in our setting; group 3). Brain oedema in the affected hemisphere was significant and ventricle symmetry was frequently disrupted. When TIQ-A $\left(10 \mathrm{mg} \cdot \mathrm{kg}^{-1}\right)$, DAMTIQ $\left(10 \mathrm{mg} \cdot \mathrm{kg}^{-1}\right)$ HYDAMTIQ $\left(1 \mathrm{mg} \cdot \mathrm{kg}^{-1}\right)$ were administered three times beginning $2 \mathrm{~h}$ after the occlu- 

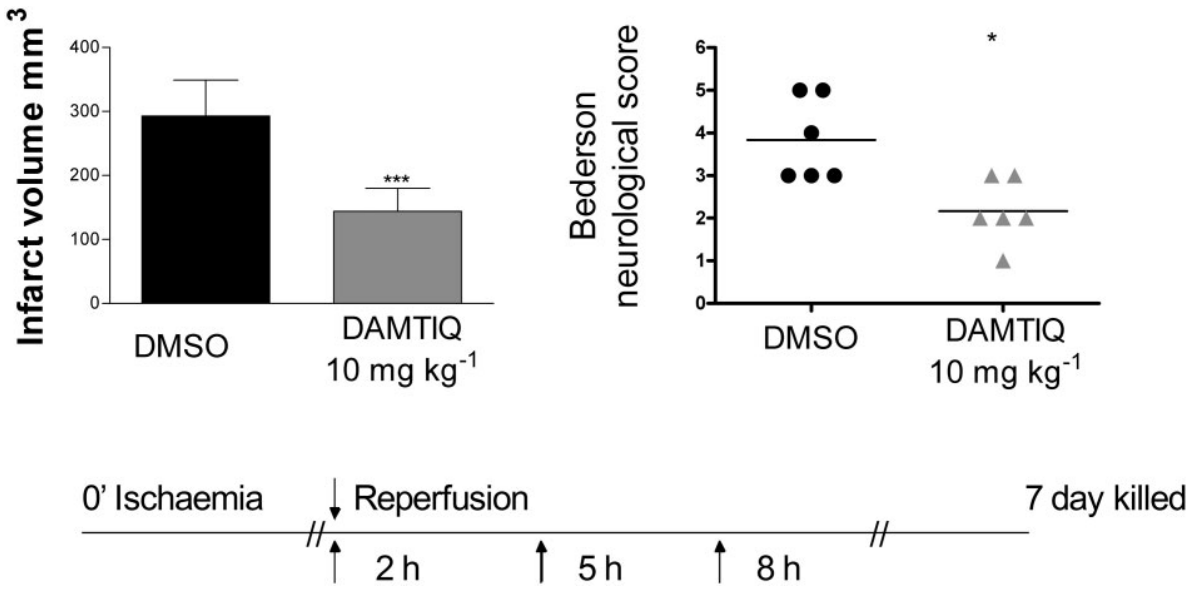

\section{Figure 5}

DAMTIQ treatment (10 mg $\cdot \mathrm{kg}^{-1}$ i.p. beginning $2 \mathrm{~h}$ after artery occlusion) reduces infarct volumes and neurological impairment 7 days after MCAO in Sprague-Dawley male rats with tMCAO (group 2). The lower panel shows the experimental protocol; the arrows show the reperfusion and the time of i.p. inhibitor administration. The left portion of the upper row reports the mean \pm SD of the infarct volumes obtained in controls (DMSO) and DAMTIQ treated rats, and the right portion of the upper row has the medians (horizontal bars) and the individual neurological scores evaluated at 7 days in the surviving animals. Two out of 8 animals in the DMSO group, and 1 out of 7 in the DAMTIQ group died. ${ }^{*}<<0.05$; *** $P<0.001$, significantly different from DMSO alone; Mann-Whitney non-parametric test.

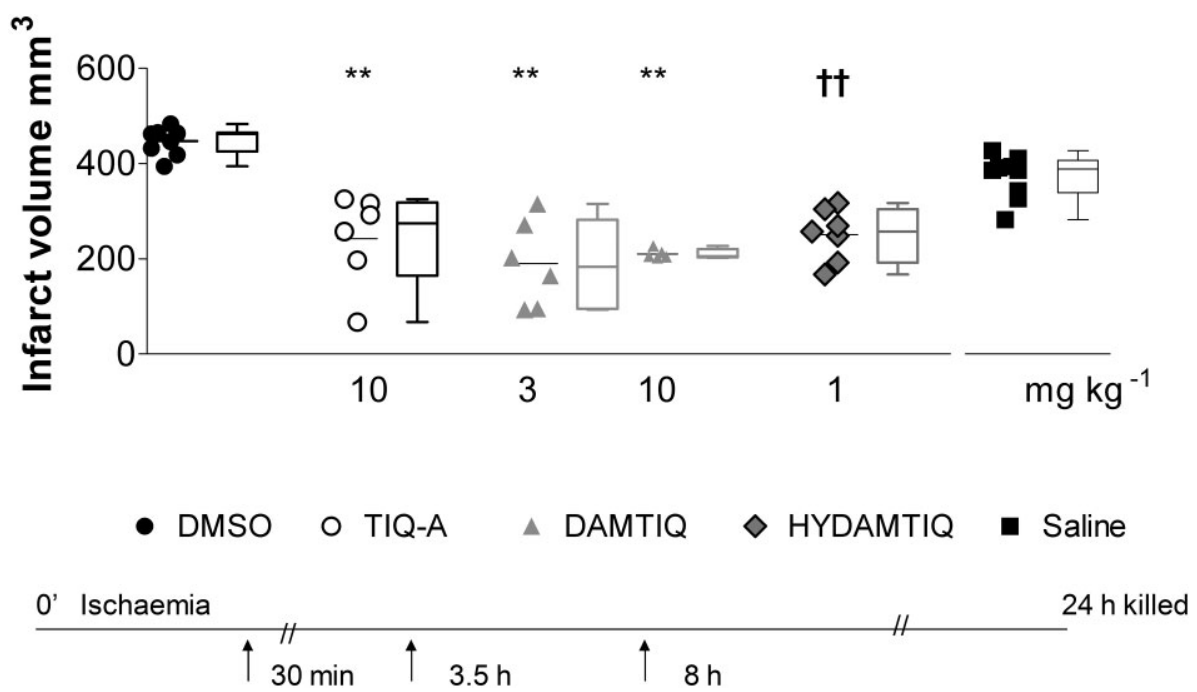

\section{Figure 6}

Infarct volumes in Sprague-Dawley rats after PMCAO (group 3; intraluminal filament left in place): neuroprotective effects of TIQ-A, DAMTIQ and HYDAMTIQ administered i.p. 30 min after the occlusion. Note that animals were evaluated $24 \mathrm{~h}$ after MCAO, and that the infarct volumes were rather large. The upper graphs show raw data and the derived box and whisker plots, defined as in Figure 1. As TIQ-A and DAMTIQ were dissolved in DMSO and HYDAMTIQ was dissolved in saline, the first and the last groups are the relative controls. Values were obtained in surviving rats; 2 out of 10 animals died in the DMSO; 2 out of 12 in the saline; 1 out of 7 in the TIQ-A $10 \mathrm{mg} \cdot \mathrm{kg}^{-1} ; 2$ out of 7 in the DAMTIQ $10 \mathrm{mg} \cdot \mathrm{kg}^{-1}$ and 1 out of 8 in the HYDAMTIQ $1 \mathrm{mg} \cdot \mathrm{kg}^{-1}$ group. ANOVA and Tukey-Kramer multiple comparisons test. ** $P<0.001$ significantly different from DMSO; $\dagger \dagger P<0.001$ significantly different from saline.

sion, no significant protection occurred. However, as reported in Figure 6, when the administration of the PARP inhibitors was initiated $30 \mathrm{~min}$ after the occlusion, a significant reduction of brain infarct volumes was obtained. TIQ-A at $10 \mathrm{mg} \cdot \mathrm{kg}^{-1}$ reduced the damage by approximately $20 \%$; DAMTIQ at $10 \mathrm{mg} \cdot \mathrm{kg}^{-1}$ by $50 \%$ and HYDAMTIQ at $1 \mathrm{mg} \cdot \mathrm{kg}^{-1}$ by $45 \%$.
DAMTIQ and HYDAMTIQ reduce the vulnerability to ischaemic brain injury of female rats subjected to tMCAO

It has been suggested that parp-1 gene deletion or the administration of suitable doses of PARP inhibitors do not reduce (actually increase) post-ischaemic brain damage in female 


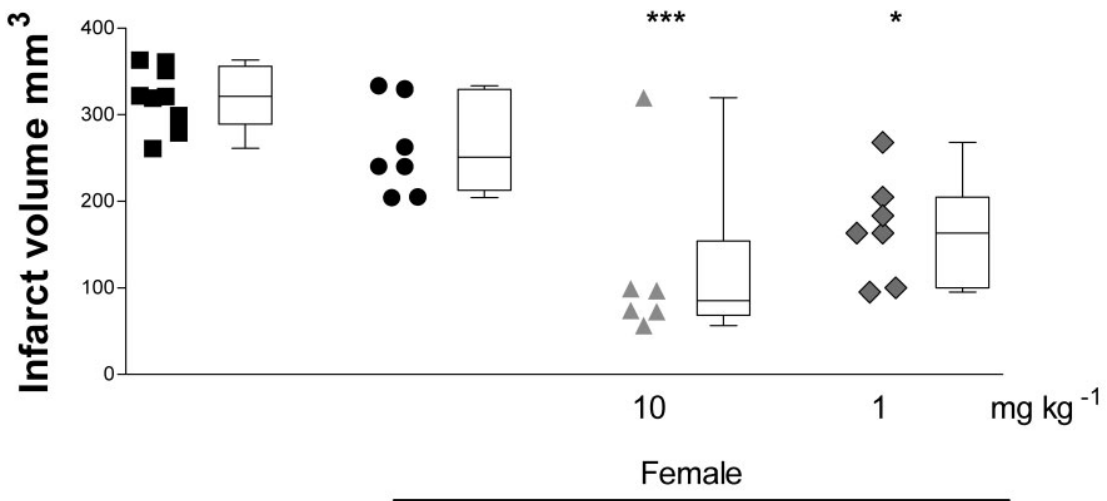

- Male Controls • Female Controls $\triangle$ DAMTIQ $\diamond$ HYDAMTIQ

\begin{tabular}{|c|c|c|}
\hline 0' Ischaemia & $\checkmark$ Reperfusion & $48 \mathrm{~h}$ killed \\
\hline
\end{tabular}

\section{Figure 7}

Infarct volumes after tMCAO in age-matched males and females: neuroprotective effects DAMTIQ (10 mg. $\mathrm{kg}^{-1}$ i.p., three times) and HYDAMTIQ $\left(1 \mathrm{mg} \cdot \mathrm{kg}^{-1}\right.$ i.p., three doses) starting $2 \mathrm{~h}$ after artery occlusion (group 4). The lower panel shows the experimental protocol; the arrows show the reperfusion and the time of i.p. inhibitor administration. The upper graphs show raw data and the derived box and whisker plots, defined as in Figure 1. Values were obtained in surviving rats. Mortality was as follows: male controls, 3 out of 22; female controls, 2 out of 10; DAMTIQ $10 \mathrm{mg} \cdot \mathrm{kg}^{-1}, 2$ out of 8 ; HYDAMTIQ $1 \mathrm{mg} \cdot \mathrm{kg}^{-1}, 1$ out of $8 .{ }^{*} P<0.05$; ${ }^{* *} P<0.01$; significantly different from female controls (MCAO + vehicle only); ANOVA and Tukey-Kramer multiple comparisons test.

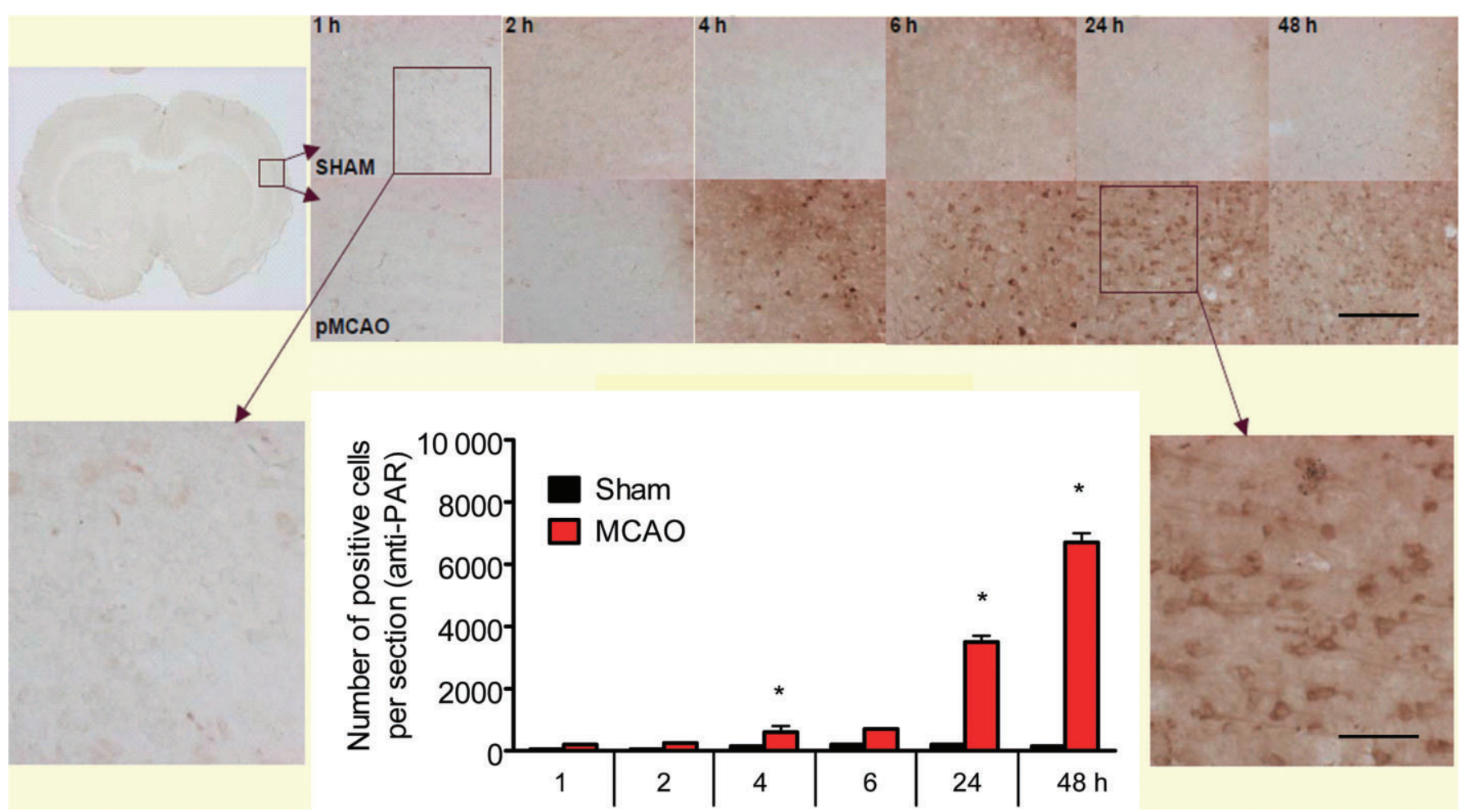

\section{Figure 8}

Time course of the appearance of PAR-positive cells in the parietal cortex of Wistar rats with electrocoagulation of the distal portion of MCA and bilateral carotid occlusion for $90 \mathrm{~min}$. Immunopositive cells were individually counted in each section. ${ }^{*} P<0.01$ significantly different from sham-operated; Student's $t$-test. Upper bar: $500 \mu \mathrm{m}$; lower bar: $50 \mu \mathrm{m}$. 


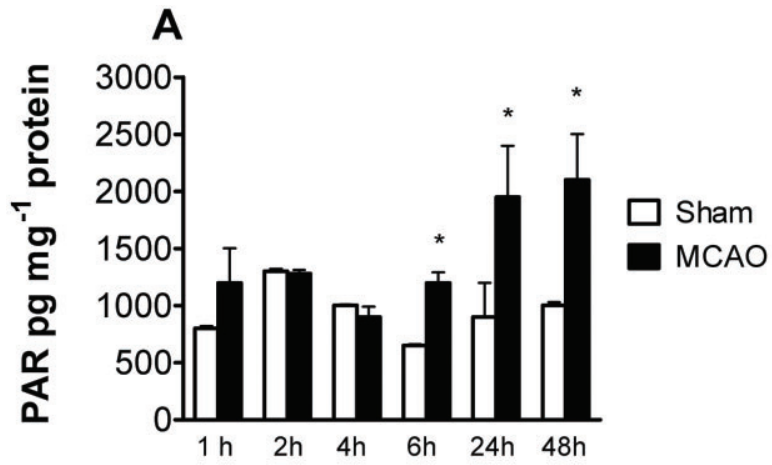

B

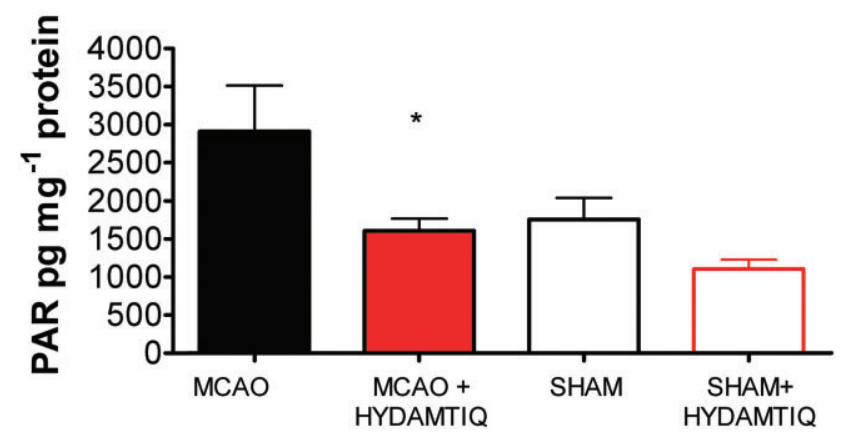

\section{Figure 9}

(A) Time course of PAR accumulation in the whole ischaemic hemisphere of MCAO Wistar rats and in sham-operated controls (group 5 ). Columns are means \pm SEM of three to five animals per group. ${ }^{*} P<0.05$ significantly different from the corresponding shamoperated group. (B) HYDAMTIQ (3.5 mg. $\mathrm{kg}^{-1}$ i.v. $4 \mathrm{~h}$ after artery occlusion plus i.v. infusion at rate of $2.5 \mathrm{mg} \cdot \mathrm{kg} \cdot \mathrm{h}^{-1}$ for $24 \mathrm{~h}$ ) reduces PAR accumulation in the parietal cortex (lesioned side) of Wistar rats killed $24 \mathrm{~h}$ after MCAO. Columns are means \pm SEM of four animals. ${ }^{*} P<0.05$ significantly different from saline-treated MCAO; ANOVA and Tukey-Kramer multiple comparisons test.

mice (McCullough et al., 2005). We used Sprague-Dawley female rats, age-matched (8-9 weeks old) to the male rats used, and we occluded their MCA for $2 \mathrm{~h}$ as described in the Methods (group 4; Table 1). Figure 7 shows that tMCAO results in smaller brain infarct volumes in females than in males $\left(318 \pm 19\right.$ in males vs. $268 \pm 35 \mathrm{~mm}^{3}$ in females; $\mathrm{P}=0.06)$, and that either DAMTIQ $\left(10 \mathrm{mg} \cdot \mathrm{kg}^{-1}\right.$ i.p. $)$ or HYDAMTIQ ( $1 \mathrm{mg} \cdot \mathrm{kg}^{-1}$ i.p.) significantly reduced these volumes.

\section{PAR accumulation after focal cortical ischaemia: effects of HYDAMTIQ}

In Wistar rats with terminal occlusion of the MCA associated with transient $(90 \mathrm{~min}$ ) ligation of common carotids (group 5; Table 1), PAR-positive cells became evident in the ischaemic cortex starting $4 \mathrm{~h}$ after MCAO. The time course of this accumulation is reported in Figure 8 . A very similar time course of PAR accumulation was obtained when PAR was directly measured in cell nuclei of the cortex or the affected brain hemisphere (Figure 9). HYDAMTIQ, administered at a dose of $3.5 \mathrm{mg} \cdot \mathrm{kg}^{-1}$ via i.v. bolus ( $4 \mathrm{~h}$ after MCAO) followed by i.v. infusion of $2.5 \mathrm{mg} \cdot \mathrm{h}^{-1}$ for $24 \mathrm{~h}$ prevented this accumulation (Figure 9B).

\section{Long-lasting effects of HYDAMTIQ treatment in rats with focal cortical ischaemia}

In order to evaluate the long-term effects of HYDAMTIQ administration in rats with focal cortical ischaemia, a group of animal was killed 21 days after surgery, and their brains were processed for immunohistochemistry studies (group 6; Table 1). As reported in Figure 10, when compared with saline-infused animals, the cortex of HYDAMTIQ-treated rats had (i) a larger number of NeuN-positive cells, (ii) a drastically reduced number of TUNEL-positive nuclei and (iii) a significantly reduced number of OX42-positive inflammatory cells. The treatment protocol above (a bolus dose of $3.5 \mathrm{mg} \cdot \mathrm{kg}^{-1}$ administered $4 \mathrm{~h}$ after surgery followed by an infusion of $2.5 \mathrm{mg} \cdot \mathrm{kg} \cdot \mathrm{h}^{-1}$ for $24 \mathrm{~h}$ ) also improved the neurological deficits and functional recovery for up to at least 3 months following treatment (group 7; Table 1 and Figure 11).

\section{Discussion}

We report here that the PARP inhibitors (TIQ-A and his two derivatives) substantially reduced brain damage after MCAO, both in male and female rats. HYDAMTIQ, the newly characterized compound studied here, is a potent and selective PARP inhibitor with an $\mathrm{IC}_{50}$ of $20 \mathrm{nM}$ and a $K_{\mathrm{d}}$ of approximately $2 \mathrm{nM}$ against PARP-1 and an $\mathrm{IC}_{50}$ of $38 \mathrm{nM}$ against PARP-2. It is water soluble and may enter the rat brain where it reaches concentrations that are sufficient to reduce PAR accumulation in the ischaemic area (see Figure 9 and Pellicciari et al., 2011). Its administration, initiated $4 \mathrm{~h}$ after artery occlusion, drastically reduced ischaemic infarct volumes and improved short- and long-term neurological impairment in different stroke models.

In the last 15 years, it has been repeatedly reported that PARP inhibitors or parp-1 gene knock-out significantly reduce post-ischaemic brain damage in rodents (see: Moroni, 2008). In the present series of experiments, we confirmed that PARP activation significantly contributed to brain damage after MCAO and we studied HYDAMTIQ following the recommendation of the stroke therapy academic industry roundtable (Fisher, 1999; Fisher et al., 2009). The compound was studied after permanent and transient MCAO, in different rat strains (Wistar and Sprague-Dawley), in both males and females and at different doses. Its window of opportunity for efficacy was determined by starting its administration at different times after MCAO and by monitoring infarct volumes and neurological improvement for up to 3 months - after the MCAO. The experiments were carried out in two independent laboratories, and the results obtained demonstrate that HYDAMTIQ provides an excellent neuroprotection with a clinically relevant therapeutic window of $4 \mathrm{~h}$. Moreover, treated animals had a reduced neurological impairment that lasted for at least 3 months. It should be mentioned, however, that our experiments were all performed in relatively young animals, and caution should be used in translating these results to the clinical situation (Endres et al., 2008). 

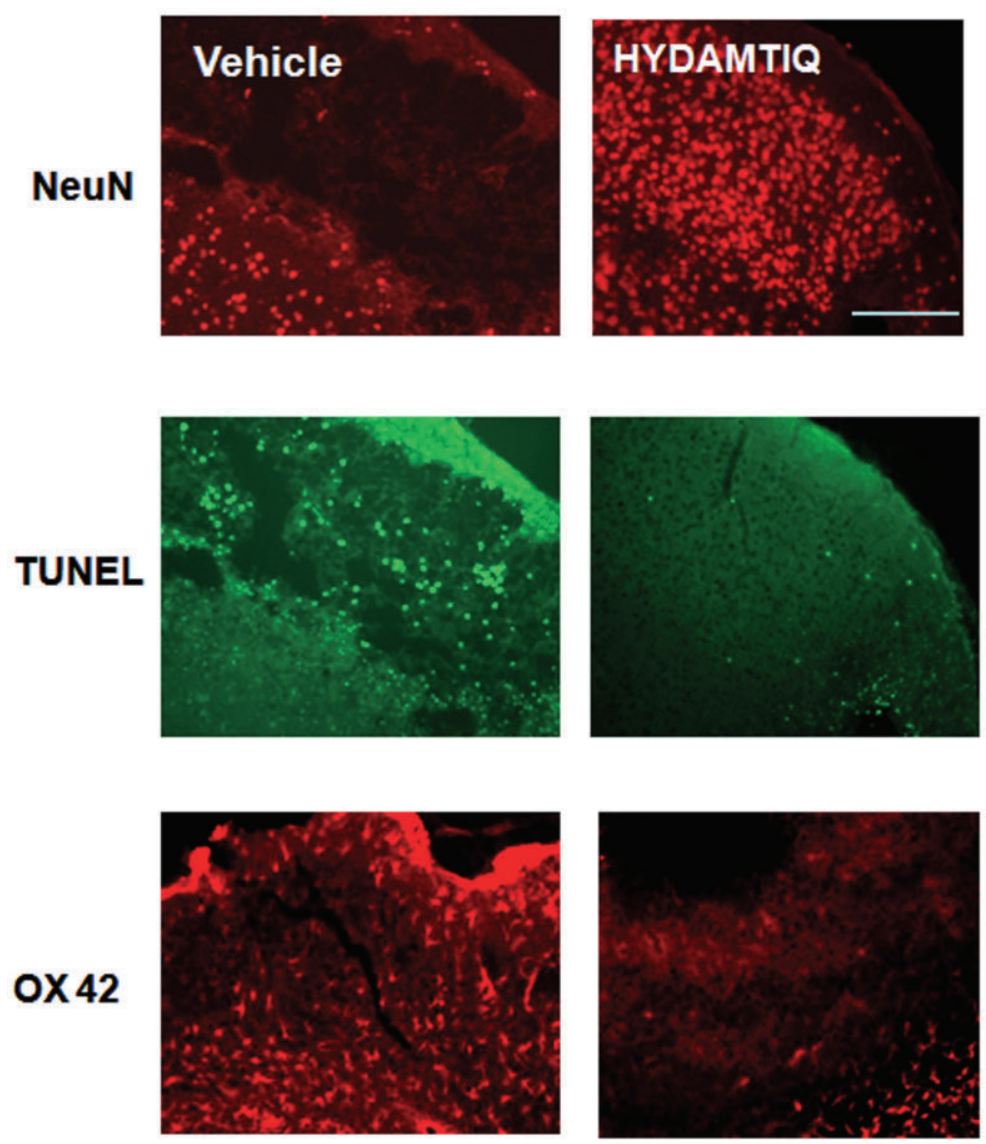
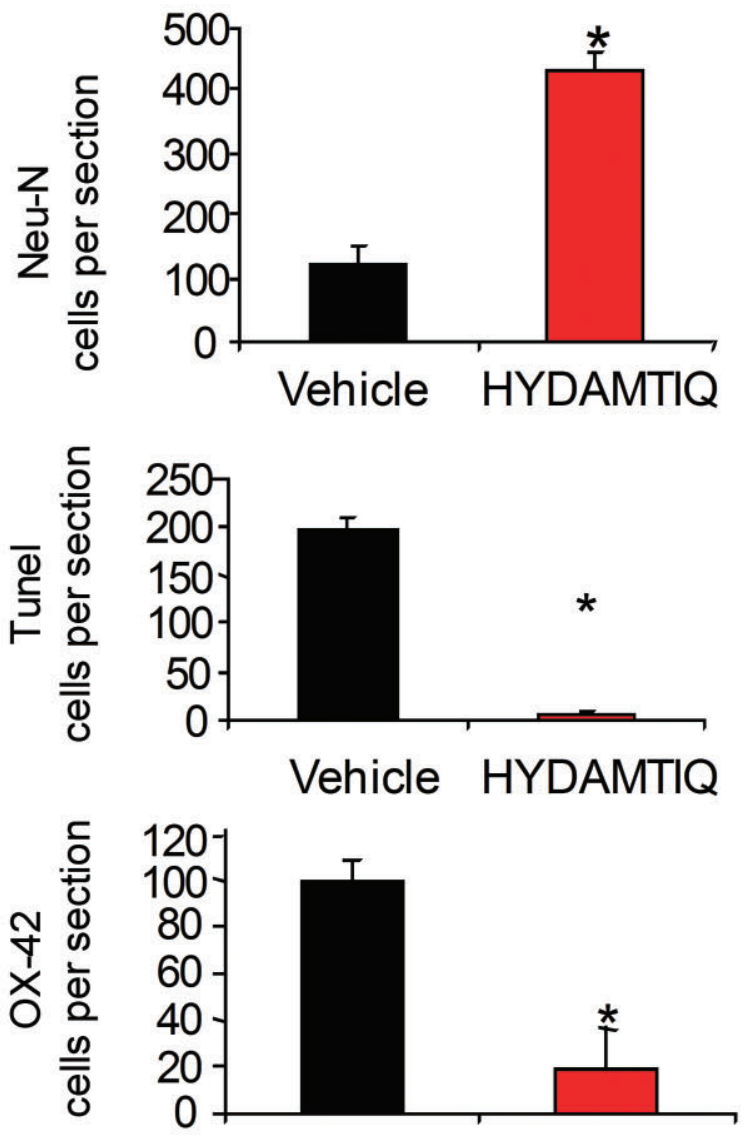

Vehicle HYDAMTIQ

\section{Figure 10}

Long-term effects of HYDAMTIQ $\left(3.5 \mathrm{mg} \cdot \mathrm{kg}^{-1}\right.$ i.v. $4 \mathrm{~h}$ after artery occlusion plus i.v. infusion at rate of $\left.2.5 \mathrm{mg} \cdot \mathrm{kg} \cdot \mathrm{h}^{-1} \mathrm{for} 24 \mathrm{~h}\right)$ on the cellular markers in the cortex of Wistar rats following permanent electrocoagulation of the distal MCAO with transient bilateral carotid occlusion (group 6). The figure shows that 21 days after HYDAMTIQ, in the dorsal cortex adjacent to the lesion, the number of NeuN-expressing cells is increased (top row), while the number of apoptotic nuclei (middle row, obtained using the 'in situ Cell Death detection kit') and the number of OX42-expressing cells (activated microglia and other inflammatory cells) are significantly reduced. All immunopositive cells were individually counted in each section. ${ }^{*} P<0.01$ significantly different from vehicle (saline); Student's $t$-test. Scale bar: $500 \mu \mathrm{m}$.

As PARP inhibitors (or the deletion of parp-1 gene) did not reduce post-ischaemic brain damage in female rodents (McCullough et al., 2005), we performed MCAO experiments both in males and in age-matched Sprague-Dawley female rats. Our results show that the infarct volumes in females were lower than those of their male counterparts. DAMTIQ or HYDAMTIQ significantly decreased the ischaemic infarct volumes also in females, but to a lesser degree (38\% reduction) than in male rats (65\% reduction). It is possible that not all the wide range of mechanisms that have been proposed to explain neuroprotection obtained with PARP inhibitors (or the deletion of parp-1 gene) are equally expressed in males and in females.

Interest in the action of these agents started in the early nineties with the demonstration that benzamide and other PARP inhibitors significantly reduced glutamate neurotoxicity in cultured cerebellar granule cells (Cosi et al., 1994). Independent work performed in the same period showed that the ischaemia-induced glutamate release resulted in NMDA receptor stimulation, massive influx of $\mathrm{Ca}^{2+}$ into the neurones, activation of $\mathrm{NO}$ synthase and a number of other enzymes with production of free radical species able to cause DNA strand breaks and pathological activation of PARP (Zhang et al., 1994). PARP inhibitors (or the deletion of parp-1 gene) blocked the depletion of both $\mathrm{NAD}^{+}$and ATP stores and preserved the energy-dependent cellular functions (Berger, 1985; Chiarugi, 2002). It was subsequently demonstrated that PARP activation may cause the release of AIF from the mitochondria and facilitates AIF translocation to the nucleus, thus activating a caspase-independent type of apoptosis that has been named par-tanathos (Yu et al., 2002; Zhang et al., 2005). This death pathway has been found in different cell types present in the brain and may contribute to the overall brain damage in stroke models. In particular, AIF-dependent apoptosis has a significant role in causing post-ischaemic endothelial damage and PARP-1 inhibitors prevent this type of injury (Zhang et al., 2005). However, while apoptosis is certainly present in the ischaemic brain regions, as confirmed in 


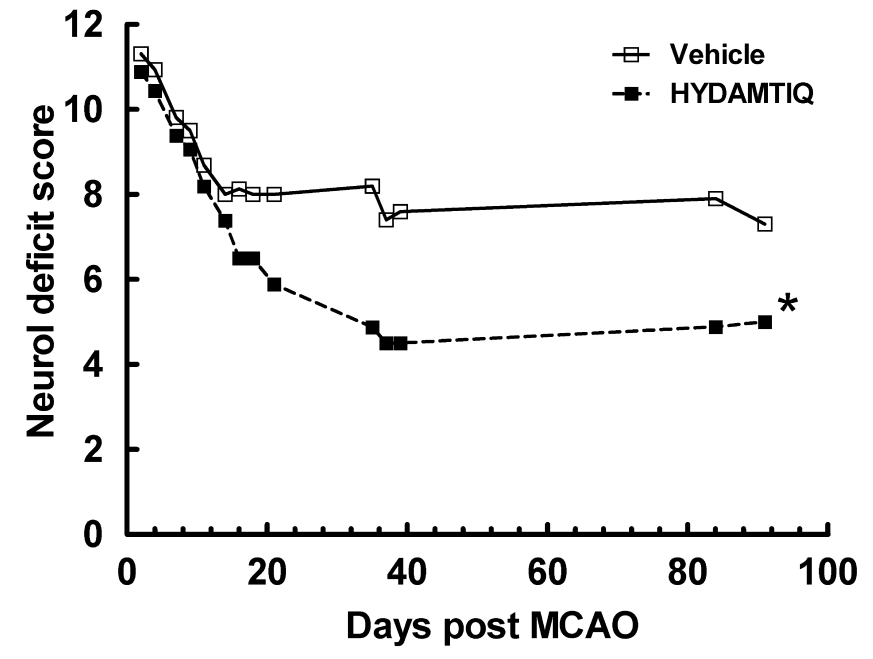

Figure 11

HYDAMTIQ treatment $\left(3.5 \mathrm{mg} \cdot \mathrm{kg}^{-1}\right.$ i.v. $4 \mathrm{~h}$ after artery occlusion plus i.v. infusion at rate of $2.5 \mathrm{mg} \cdot \mathrm{kg} \cdot \mathrm{h}^{-1}$ for $24 \mathrm{~h}$ ) results in long-lasting improvement of functional recovery (group 7). Values are means of at least seven animals per group. ${ }^{\star} P<0.05$, significant effect of HYDAMTIQ.

the present work, it is certainly not the predominant mechanism of cell death after MCAO (Dirnagl et al., 1999) and it is not particularly frequent in post-ischaemic neurones (Moroni et al., 2001).

A number of other molecular mechanisms linking PARP activation to post-ischaemic brain damage have been proposed in either neuronal or non-neuronal cells: PARPs control gene expression by interacting with a number of transcription factors and with specific DNA sequences, thus promoting enhanceosome aggregation and gene transcription (Chiarugi, 2002; Kraus and Lis, 2003). Other epigenetic mechanisms involving either PARP molecules or their enzymic activities have been recently described (Caiafa et al., 2009). In particular, excessive PARP activation contributes to increased expression of pro-inflammatory enzymes and reduced expression of pro-survival factors (Koh et al., 2004). Also, PAR metabolism results in the formation of metabolite(s) able to hamper mitochondrial function (Cipriani et al., 2005; Andrabi et al., 2006; Yu et al., 2006) and facilitate cell death. Other proposed molecular mechanisms linking excessive PARP activation to post-ischaemic brain damage are: the PAR-mediated opening of a transient receptor potential cation channel (TRPM2) and an excessive inflow of $\mathrm{Ca}^{2+}$ (Fonfria et al., 2004) or an enhanced expression of MMP-9 with increased blood-brain barrier permeability and brain oedema (Lescot et al., 2010). It is reasonable to assume that not all these molecular mechanisms of brain damage are identical in males and females, and this could explain why neuroprotection by PARP inhibitors was less in females.

A significant accumulation of PAR, the product of PARP activity, was found in post-ischaemic cortical cells starting $4 \mathrm{~h}$ after MCAO and reaching very high levels of PAR-positive cells $48 \mathrm{~h}$ after artery occlusion. These results parallel the time course of DNA damage in the brain after MCAO (Giovannelli et al., 2002), strongly suggesting that DNA lesions activate PARP and cause excessive PAR accumulation in brain cells (de Murcia et al., 1992). PAR accumulates not only in neurones but also in glia and other cell types present in the neurovascular unit and damaged by the ischaemic challenge (see: Moroni and Chiarugi, 2009). As PARP activation may be deleterious for these cells, it is possible that PARP inhibitors, by protecting not only neurones but also glial, vascular and inflammatory cells, are particularly effective in reducing stroke-induced brain damage.

It has been proposed that one of the reasons for the lack of efficacy of the many neuroprotective drugs so far tested in clinical trials, could be the selectivity of their action: for instance, glutamate antagonists act exclusively (or predominantly) on neurones. When endothelia and glial cells are damaged, neurones cannot survive in spite of protection from excitotoxic insults. Similarly, selectively blocking apoptosis or inflammation within the ischaemic tissue cannot provide protection when the other detrimental events are unrestricted. As PARP inhibitors are able to interact with all cell types of the neurovascular unit and also to preserve the blood-brain barrier (Lenzser et al., 2007), their eventual use in clinical practice could provide a better outcome than other 'neuroprotective' strategies so far tested. Finally, PARP has been associated with activation of microglia and an increased expression of neurotoxic inflammatory mediators (Kauppinen and Swanson, 2005). It is interesting to note that 21 days after MCAO, in the cortex of HYDAMTIQ-treated animals, the presence of OX42-positive inflammatory cells was drastically reduced, thus confirming that the antiinflammatory action of PARP inhibitors may contribute to the final effects we observed.

Taken together, our results shows that HYDAMTIQ is a potent PARP inhibitor that, when administered within $4 \mathrm{~h}$ after artery occlusion, reduces brain damage in different stroke models in rats. Neuroprotection was robust; it was present both in males and females and it was associated with long-term (up to 3 months) improvement of neurological impairments.

\section{Acknowledgements}

This work was supported by Wyeth Research Laboratories; University of Florence; University of Perugia and Ente Cassa di Risparmio di Firenze.

\section{Conflicts of interest}

Roberto Pellicciari and Flavio Moroni have patent applications on HYDAMTIQ and other PARP inhibitors.

\section{References}

Alexander SPH, Mathie A, Peters JA (2011). Guide to Receptors and Channels (GRAC), 5th edn. Br J Pharmacol 164 (Suppl. 1): S1-S324.

Andrabi SA, Kim NS, Yu SW, Wang H, Koh DW, Sasaki M et al. (2006). Poly(ADP-ribose) (PAR) polymer is a death signal. Proc Natl Acad Sci USA 103: 18308-18313. 
Bederson JB, Pitts LH, Tsuji M, Nishimura MC, Davis RL, Bartkowski H (1986). Rat middle cerebral artery occlusion: evaluation of the model and development of a neurologic examination. Stroke 17: 472-476.

Berger NA (1985). Poly(ADP-ribose) in the cellular response to DNA damage. Radiat Res 101: 4-15.

Caiafa P, Guastafierro T, Zampieri M (2009). Epigenetics: poly(ADP-ribosyl)ation of PARP-1 regulates genomic methylation patterns. FASEB J 23: 672-678.

Chen ST, Hsu CY, Hogan EL, Maricq H, Balentine JD (1986). A model of focal ischemic stroke in the rat: reproducible extensive cortical infarction. Stroke 17: 738-743.

Chiarugi A (2002). Poly(ADP-ribose)polymerase: killer or conspirator? The 'suicide hypothesis' revisited. Trends Pharmacol Sci 23: 122-129.

Chiarugi A, Moskowitz MA (2003). Poly(ADP-ribose) polymerase-1 activity promotes NF-kappaB-driven transcription and microglial activation: implication for neurodegenerative disorders. J Neurochem 85: 306-317.

Chiarugi A, Meli E, Calvani M, Picca R, Baronti R, Camaioni E et al. (2003). Novel isoquinolinone-derived inhibitors of poly(ADP-ribose) polymerase-1: pharmacological characterization and neuroprotective effects in an in vitro model of cerebral ischemia. J Pharmacol Exp Ther 305: 943-949.

Cipriani G, Rapizzi E, Vannacci A, Rizzuto R, Moroni F, Chiarugi A (2005). Nuclear poly(ADP-ribose) polymerase-1 rapidly triggers mitochondrial dysfunction. J Biol Chem 280: 17227-17234.

Cosi C, Suzuki H, Milani D, Facci L, Menegazzi M, Vantini G et al. (1994). Poly(ADP-ribose)polymerase: early involvement in glutamate-induced neurotoxicity in cultured cerebellar granule cells. J Neurosci Res 39: 38-46.

Cozzi A, Cipriani G, Fossati S, Faraco G, Formentini L, Min W et al. (2006). Poly(ADP-ribose) accumulation and enhancement of postischemic brain damage in 110-kDa poly(ADP-ribose) glycohydrolase null mice. J Cereb Blood Flow Metab 26: 684-695.

De Murcia G, Menisser-de Murcia J, Schreiber V (1992). Poly(ADP-ribose)polymerase: a molecular nick sensor. Trends Biochem Sci 19: 172-176.

De Ryck M, Van Reempts J, Borgers M, Wauquier A, Janssen PA (1989). Photochemical stroke model: flunarizine prevents sensorimotor deficits after neocortical infarcts in rats. Stroke 20: 1383-1390.

Dirnagl U, Iadecola C, Moskowitz MA (1999). Pathobiology of ischaemic stroke: an integrated view. Trends Neurosci 22: 391-397.

Egi Y, Matsuura S, Maruyama T, Fujio M, Yuki S, Akira T (2011). Neuroprotective effects of a novel water-soluble poly(ADP-ribose) polymerase-1 inhibitor, MP-124, in in vitro and in vivo models of cerebral ischemia. Brain Res 1389: 169-176.

Eliasson MJ, Sampei K, Mandir AS, Hurn PD, Traystman RJ, Bao J (1997). Poly(ADP-ribose) polymerase gene disruption renders mice resistant to cerebral ischemia. Nat Med 3: 1089-1095.

Endres M, Wang ZQ, Namura S, Waeber C, Moskowitz MA (1997). Ischemic brain injury is mediated by the activation of poly(ADP-ribose)polymerase. J Cereb Blood Flow Metab 17: 1143-1151.

Endres M, Engelhardt B, Koistinaho J, Lindvall O, Meairs S, Mohr JP et al. (2008). Improving outcome after stroke: overcoming the translational roadblock. Cerebrovasc Dis 25: 268-278.
Ferraris DV (2010). Evolution of poly(ADP-ribose) polymerase-1 (PARP-1) inhibitors. From concept to clinic. J Med Chem 53: 4561-4584.

Fisher M (1999). Recommendations for standards regarding preclinical neuroprotective and restorative drug development. Stroke 30: 2752-2758.

Fisher M, Feuerstein G, Howells DW, Hurn PD, Kent TA, Savitz SI et al. (2009). Update of the stroke therapy academic industry roundtable preclinical recommendations. Stroke 40: 2244-2250.

Fonfria E, Marshall IC, Benham CD, Boyfield I, Brown JD, Hill K et al. (2004). TRPM2 channel opening in response to oxidative stress is dependent on activation of poly(ADP-ribose) polymerase. Br J Pharmacol 143: 186-192.

Giovannelli L, Cozzi A, Guarnieri I, Dolara P, Moroni F (2002). Comet assay as a novel approach for studying DNA damage in focal cerebral ischemia: differential effects of NMDA receptor antagonists and poly(ADP-ribose) polymerase inhibitors. J Cereb Blood Flow Metab 22: 697-704.

Ha HC, Snyder SH (1999). Poly(ADP-ribose) polymerase is a mediator of necrotic cell death by ATP depletion. Proc Natl Acad Sci USA 96: 13978-13982.

Haddad M, Beray-Berthat V, Coqueran B, Palmier B, Szabo C, Plotkine $M$ et al. (2008). Reduction of hemorrhagic transformation by PJ34, a poly(ADP-ribose)polymerase inhibitor, after permanent focal cerebral ischemia in mice. Eur J Pharmacol 588: 52-57.

Hagberg H, Wilson MA, Matsushita H, Zhu C, Lange M, Gustavsson M et al. (2004). PARP-1 gene disruption in mice preferentially protects males from perinatal brain injury. J Neurochem 90: 1068-1075.

Hottiger MO, Hassa PO, Luscher B, Schuler H, Koch-Nolte F (2010). Toward a unified nomenclature for mammalian ADP-ribosyltransferases. Trends Biochem Sci 35: 208-219.

Jagtap P, Szabo C (2005). Poly(ADP-ribose) polymerase and the therapeutic effects of its inhibitors. Nat Rev Drug Discov 4: $421-440$.

Kauppinen TM, Swanson RA (2005). Poly(ADP-ribose) polymerase-1 promotes microglial activation, proliferation, and matrix metalloproteinase-9-mediated neuron death. J Immunol 174: 2288-2296.

Koh SH, Park Y, Song CW, Kim JG, Kim K, Kim J et al. (2004). The effect of PARP inhibitor on ischaemic cell death, its related inflammation and survival signals. Eur J Neurosci 20: 1461-1472.

Kraus WL, Lis JT (2003). PARP goes transcription. Cell 113: $677-683$.

Lenzser G, Kis B, Snipes JA, Gaspar T, Sandor P, Komjati K et al. (2007). Contribution of poly(ADP-ribose) polymerase to postischemic blood-brain barrier damage in rats. J Cereb Blood Flow Metab 27: 1318-1326.

Lescot T, Fulla-Oller L, Palmier B, Po C, Beziaud T, Puybasset L et al. (2010). Effect of acute poly(ADP-ribose) polymerase inhibition by $3-\mathrm{AB}$ on blood-brain barrier permeability and edema formation after focal traumatic brain injury in rats. J Neurotrauma 27: 1069-1079.

Liu X, Palma J, Kinders R, Shi Y, Donawho C, Ellis PA et al. (2008). An enzyme-linked immunosorbent poly(ADP-ribose) polymerase biomarker assay for clinical trials of PARP inhibitors. Anal Biochem 381: 240-247. 
Longa EZ, Weinstein PR, Carlson S, Cummins R (1989). Reversible middle cerebral artery occlusion without craniectomy in rats. Stroke 20: 84-91.

McCullough LD, Zeng Z, Blizzard KK, Debchoudhury I, Hurn PD (2005). Ischemic nitric oxide and poly (ADP-ribose) polymerase-1 in cerebral ischemia: male toxicity, female protection. J Cereb Blood Flow Metab 25: 502-512.

Moroni F (2008). Poly(ADP-ribose)polymerase 1 (PARP-1) and postischemic brain damage. Curr Opin Pharmacol 8: 96-103.

Moroni F, Chiarugi A (2009). Post-ischemic brain damage: targeting PARP-1 within the ischemic neurovascular units as a realistic avenue to stroke treatment. FEBS J 276: 36-45.

Moroni F, Meli E, Peruginelli F, Chiarugi A, Cozzi A, Picca R et al. (2001). Poly(ADP-ribose) polymerase inhibitors attenuate necrotic but not apoptotic neuronal death in experimental models of cerebral ischemia. Cell Death Differ 8: 921-932.

Moroni F, Attucci S, Cozzi A, Meli E, Picca R, Scheideler MA et al. (2002). The novel and systemically active metabotropic glutamate 1 (mGlu1) receptor antagonist 3-MATIDA reduces post-ischemic neuronal death. Neuropharmacology 42: 741-751.

Moroni F, Formentini L, Gerace E, Camaioni E, Pellegrini-Giampietro DE, Chiarugi A et al. (2009). Selective PARP-2 inhibitors increase apoptosis in hippocampal slices but protect cortical cells in models of post-ischaemic brain damage. Br J Pharmacol 157: 854-862.

Pellicciari R, Camaioni E, Costantino G, Marinozzi M, Macchiarulo A, Moroni F et al. (2003). Towards new neuroprotective agents: design and synthesis of $4 \mathrm{H}$-thieno[2,3-c] isoquinolin-5-one derivatives as potent PARP-1 inhibitors. Farmaco 58: 851-858.
Pellicciari R, Camaioni E, Gilbert AM, Macchiarulo A, Bikker JA, Shah F et al. (2011). Discovery and characterization of novel potent PARP-1 inhibitors endowed with neuroprotective properties: from TIQ-A to HYDAMTIQ. Med Chem Commun 2: 559-565.

Schreiber V, Dantzer F, Ame JC, de Murcia G (2006).

Poly(ADP-ribose): novel functions for an old molecule. Nat Rev Mol Cell Biol 7: 517-528.

Szabo C, Dawson VL (1998). Role of poly(ADP-ribose) synthetase in inflammation and ischaemia-reperfusion. Trends Pharmacol Sci 19: 287-298.

Yu SW, Wang H, Poitras MF, Coombs C, Bowers WJ, Federoff HJ et al. (2002). Mediation of poly(ADP-ribose) polymerase-1dependent cell death by apoptosis-inducing factor. Science 297: 259-263.

Yu SW, Andrabi SA, Wang H, Kim NS, Poirier GG, Dawson TM et al. (2006). Apoptosis-inducing factor mediates poly(ADP-ribose) (PAR) polymer-induced cell death. Proc Natl Acad Sci USA 103: 18314-18319.

Yuan M, Siegel C, Zeng Z, Li J, Liu F, McCullough LD (2009). Sex differences in the response to activation of the poly (ADP-ribose) polymerase pathway after experimental stroke. Exp Neurol 217: 210-218.

Zhang Y, Dawson VL, Dawson TM, Snyder SH (1994). Nitric oxide activation of poli(ADP-ribose)synthetase in neurotoxicity. Science 263: 687-689.

Zhang Y, Zhang X, Park TS, Gidday JM (2005). Cerebral endothelial cell apoptosis after ischemia-reperfusion: role of PARP activation and AIF translocation. J Cereb Blood Flow Metab 25: 868-877. 